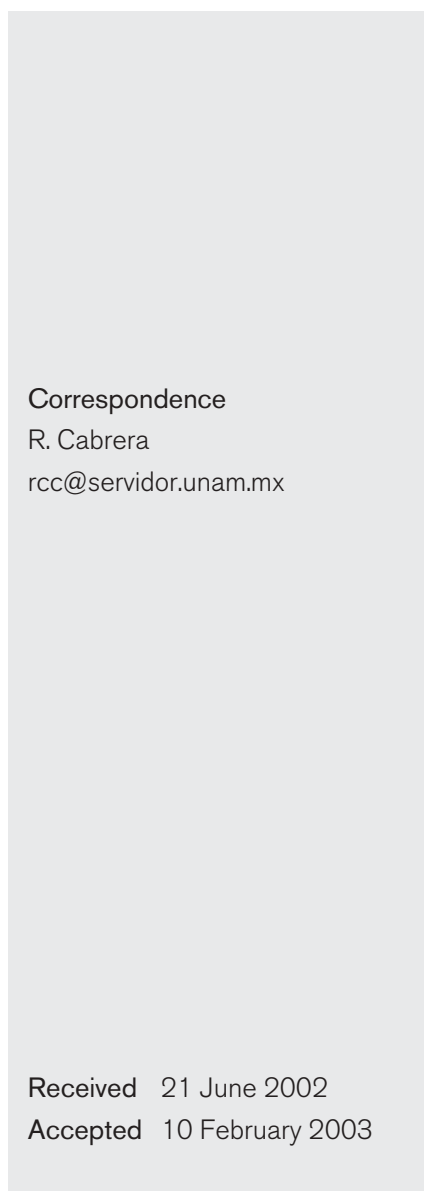

\section{Comparative viral frequency in Mexican children under 5 years of age with and without upper respiratory symptoms}

\author{
M. E. Manjarrez, ${ }^{1}$ D. P. Rosete, ${ }^{1}$ M. Rincón, ${ }^{2}$ J. Villalba, ${ }^{1}$ A. Cravioto ${ }^{2}$ \\ and R. Cabrera ${ }^{2}$ \\ ${ }^{1}$ Departamento de Investigación en Virología, Instituto Nacional de Enfermedades Respiratorias
(INER), México DF 14080, Mexico \\ ${ }^{2}$ Departamento de Salud Pública, Facultad de Medicina, Universidad Nacional Autónoma de México \\ (UNAM), México DF 04510, Mexico
}

\section{INTRODUCTION}

According to a report by the World Health Organization (1993), over 15 million deaths occur annually worldwide in children under 5 years of age. Most of this mortality (97\%) occurs in developing countries, and more than $25 \%$ of these infant deaths are caused by acute respiratory infections (ARIs) (Benguigui, 1996).

Infectious diseases are still one of the main causes of morbidity and mortality in the developing world (Degré, 1986; Douglas, 1990; Graham, 1990; Working Group on ARI, Respiratory Disease Committee, 1993; Denny, 1995; Cravioto et al., 1998; Makela et al., 1998; Videla et al., 1998; Nelson et al., 1999). ARI is the main cause of infant death. The highest mortality due to ARI occurs in the African continent and Central America, followed by South America and Asia (Douglas, 1990; Cravioto et al., 1998). The most important aetiological agents of ARI in humans are primary

Abbreviations: Ad, adenovirus; $A R I$, acute respiratory infection; CPE, cytopathic effect; IA, influenza virus group A; IB, influenza virus group B; IIF, indirect immunofluorescence; $\mathrm{Pl}$, parainfluenza virus; RSV, respiratory syncytial virus. viruses (95\%) and secondary bacteria (Degré, 1986; Douglas, 1990; Graham, 1990; Benguigui, 1996; Cravioto et al., 1998; Makela et al., 1998).

It is well-known that, worldwide, children under 5 years of age are more susceptible to ARI (Graham, 1990; Denny, 1995; Benguigui, 1996). Respiratory symptoms are usually complicated in this particular age group and, as a consequence, the severity of ARI cases is also increased (Working Group on ARI, Respiratory Disease Committee, 1993; Denny, 1995; Makela et al., 1998).

In general, there are several possible aetiological agents that cause the majority of ARI, the main ones being influenza groups A and B (IA, IB), parainfluenza (types 1, 2 and 3; PI), respiratory syncytial viruses (RSV) and adenovirus (Ad), followed by others such as rhinovirus (Rh), coronavirus $(\mathrm{Cn})$ and enterovirus (Et) (Working Group on ARI, Respiratory Disease Committee, 1993; Makela et al., 1998; Nelson et al., 1999).

In Mexico in 1999, there was a high incidence of ARI in children under 5 years of age, with morbidity and mortality rates of $27575 \cdot 5 / 100000$ and $47 \cdot 3 / 100000$, respectively (Benguigui, 1988; Secretaría de Salud, 1999). These data show why ARI forms the main impetus for requesting health services (Secretaría de Salud, 1999). Viral infections are 
frequently followed by bacterial superinfections and, as a consequence, respiratory symptoms are usually complicated (Degré, 1986).

The children in the present study were from the Nezahualcóyotl City area, the population of which is commonly subjected to various infectious diseases. Nezahualcóyotl City is adjacent to Mexico City; by 1998, it had a population of over 1.6 million inhabitants, of which $13 \%$ were in the $0-4$ year age group. Many of these children are from low-income families; immigrants from an area of the dry Texcoco Lake form a large proportion of the population. The climate of this deforested area is mild, with frequent dust storms in the dry season. The high frequency of ARI in children under 5 years of age in Nezahualcóyotl City and a lack of knowledge about the viral agents involved, together with associated risk factors, provoke the need for fundamental epidemiological and clinical information, which could then be used to help to provide prompt and efficient attention to these cases and to develop strategies for both control and prophylaxis in the future.

The aim of this study was to compare the frequency of respiratory viruses in 179 patients with ARI against 179 ARIfree subjects with normal airway function. This is one of the first analytical studies of ARI to be carried out in the region.

\section{METHODS}

This analytical study was set up as a collaboration between two primary health-care units and one academic institution: a third-level medical centre, namely the National Institute of Respiratory Diseases (INER, Virology Department), a metropolitan centre ('Urbano Metropolitana') at the Mexican State Institute of Health (ISEM) and the Faculty of Medicine at the National Autonomous University of Mexico (UNAM).

Study population. All subjects were under 5 years of age. Children with ARI (cases) were identified when their parents requested medical attention at the 'Urbano Metropolitana' health centre. A child without ARI (control) was identified for each case of ARI, by selecting an infant from the general population who had not had signs or symptoms of ARI during the previous 30 days and was in the same age group. Written informed consent was obtained from parents of children selected to enter this study. A group of 358 children (179 with ARI and 179 controls) was selected from this medical centre, which has 25000 children registered in total.

Samples from children with and without ARI were collected between 1995 and 1996, during two seasonal periods: winter-spring (DecemberMay; cases, 53 positive samples/112 vs controls, 32/119) and summerautumn (June-December; cases, 35/67 vs controls, 17/60).

ARI definition. Children were considered to be a case of ARI if they presented with one or more of the following clinical signs or symptoms: nasal discharge or congestion, sneezing, sore throat, cough, low-grade fever and rapid or noisy breathing.

Specimen collection. A nasopharyngeal (NP) swab culture was obtained from each case of ARI and control subject during the study period. A calcium alginate swab on an ultra-flexible aluminium shaft (Calgiswab; Spectrum Laboratories) was used for this purpose. Each NP sample was used to inoculate $3 \mathrm{ml}$ Leibovitz L-15 sterile solution (In vitro, S. A., México), which was used as a transport medium in glass assay tubes with screw caps. All samples were kept refrigerated at $4{ }^{\circ} \mathrm{C}$ until use.
Detection of respiratory viruses. Samples were centrifuged and supernatants were inoculated onto monolayers of the HEp-2, HeLa and Vero cell lines with Minimum Essential medium (MEM; Sigma). Adsorption was performed at $37^{\circ} \mathrm{C}$ in $5 \% \mathrm{CO}_{2}$ over $60 \mathrm{~min}$. Cell cultures were washed once with $\mathrm{PBS}(\mathrm{pH} 7 \cdot 2$ ), followed by the addition of fresh MEM. All cultures were incubated for 10 days under the same conditions as for adsorption. Infected cells were checked on a daily basis by looking for the characteristic cytopathic effect (CPE). If a CPEnegative result was observed after 10 days incubation, a subculture was performed over 5 days. If a CPE-negative result was still observed from this first subculture, then a second subculture was performed over a further 5 days. If a CPE-negative result was obtained from the second subculture, then a negative result was recorded for this test. Cells that were positive for CPE during the initial incubation or after the first or second subcultures were specifically stained by indirect immunofluorescence (IIF) testing. Cells that were CPE-negative after the second subculture were also stained by IIF. Cells that were CPE-negative during the initial incubation or after the first subculture were not stained. Specifically, all inoculated cells that were CPE-positive or -negative were fixed with $4 \%$ formaldehyde and processed by IIF, which used mAbs against the following viruses: IA, IB, PI types 1, 2 and 3, RSV and Ad [Influenza A and B Imagen kit, Parainfluenza group (types 1, 2 and 3) Imagen kit, Respiratory Syncytial Virus Imagen kit and Adenovirus Imagen kit; all from Dako]. These kits contain an immunological reagent that has a $\mathrm{mAb}$ directed to a common antigen present in each of the 42 reported serotypes of human adenovirus.

Statistical analysis. A $\chi^{2}$ test was used to compare differences in viral types and frequencies between different age groups of children with and without ARI. A probability value of $\leqslant 5 \%$ was considered to be statistically significant (Hosmer, 1992). Approximate $P$ values were determined using EPI-INFO software, version 6.04.

\section{RESULTS}

Patients were classified into five groups according to age: group $\mathrm{A},<1$ year; group $\mathrm{B}$, from 1 to $<2$ years; group $\mathrm{C}$, from 2 to $<3$ years; group $\mathrm{D}$, from 3 to $<4$ years; and group E, from 4 to 5 years (Table 1). Sex differences between the five groups were minimal and not statistically significant.

The frequency of virus isolation in children with ARI compared to children without ARI is shown by age group in Table 1. In the group of children with ARI, viral isolates were obtained most frequently from groups A, C and D (56, 54 and $50 \%$, respectively; Table 1$)$. The highest frequency of viral infection was found in group A ( $<1$ year of age). Total viral infection in the children with ARI (88/179) was also highly significant $(P<0.004)$ when compared with total viral infection in the children without ARI (49/179). A statistical significance was not observed between the other four age groups, B-E (Table 1).

The highest frequencies of viral infection in children without ARI were observed in older age groups: group $C$ showed the most frequent rate of viral infection at $35 \%$, followed by groups D and B (32 and $31 \%$, respectively; Table 1).

A total of $97.5 \%(83 / 88)$ viral isolates were detected by CPE in cell cultures [ $36 \cdot 4 \%$ after the first culture (31/88), $54 \cdot 1 \%$ in the first subculture $(46 / 88)$ and $7 \%$ in the second subculture $(8 / 88)] ; 100 \%(88 / 88)$ of these viruses were identified by IIF. Types of viral isolates for each group are shown in Table 2. Among the 88 viral isolates from children 
Table 1. Frequency of virus isolation in Mexican children with and without ARI by age group

\begin{tabular}{|c|c|c|c|c|c|c|}
\hline \multirow[t]{2}{*}{ Group } & \multirow[t]{2}{*}{ Age (years) } & \multicolumn{2}{|c|}{ ARI-positive } & \multicolumn{2}{|c|}{ ARI-negative } & \multirow[t]{2}{*}{$P$ value } \\
\hline & & $n /$ total $^{\star}$ & $(\%)$ & $n /$ total $^{\star}$ & $(\%)$ & \\
\hline A & $<1$ & $22 / 39$ & 56 & $6 / 36$ & 17 & $0 \cdot 05 \dagger$ \\
\hline B & 1 to $<2$ & $12 / 30$ & 40 & $9 / 29$ & 31 & NS末 \\
\hline C & 2 to $<3$ & $22 / 41$ & 54 & $16 / 46$ & 35 & NS \\
\hline $\mathrm{D}$ & 3 to $<4$ & $21 / 42$ & 50 & $11 / 34$ & 32 & NS $\ddagger$ \\
\hline $\mathrm{E}$ & 4 to $<5$ & $11 / 26$ & 40 & $7 / 34$ & 21 & NS $\ddagger$ \\
\hline Total positive & - & 88 & 49 & 49 & 27 & $0 \cdot 03 \dagger$ \\
\hline Total children & - & 179 & - & 179 & - & $0 \cdot 004 \dagger$ \\
\hline
\end{tabular}

${ }^{*}$ Number of samples with positive respiratory viruses in relation to the total number of children with ARI (positive) or without ARI (negative) by age group.

$\dagger P \leqslant 0.05$ by $\chi^{2}$ test of children with ARI compared to children without ARI (\%), respectively.

$\ddagger$ NS, Not statistically significant.

with ARI, the most frequent was RSV (38\%), followed by Ad (19\%), PI (17\%), IA (16\%) and finally IB (10\%) (Table 2). Several viruses were also isolated from the group of children without ARI (Table 2). The most frequent were IA and PI (both $22 \%$ ) but in contrast to the children with ARI, the subsequent order of frequency was Ad (20\%) and RSV $(18 \%)$ and IB $(18 \%)$.

Variation over time of respiratory viruses in children with or without ARI is shown in Fig. 1. A higher seasonal incidence of respiratory viruses in both groups of children was observed during the winter-spring period (Fig. 1). The lowest

Table 2. Positive respiratory virus types in Mexican children with and without ARI

\begin{tabular}{|lrrrrrr|}
\hline Virus type & \multicolumn{2}{c}{ ARI-positive } & & \multicolumn{2}{c|}{ ARI-negative } & \multirow{2}{*}{$\boldsymbol{P}$ value } \\
\cline { 2 - 3 } & $\boldsymbol{n}^{*}$ & $(\%)$ & & $\boldsymbol{n}^{*}$ & $(\%)$ & \\
\cline { 1 - 2 } & 17 & 19 & & 10 & 20 & NS $\dagger$ \\
Ad & 14 & 16 & & 11 & 22 & NS $\dagger$ \\
IA & 9 & 10 & & 9 & 18 & NS $\dagger$ \\
IB & 15 & 17 & & 10 & 22 & NS $\dagger$ \\
PI types 1-3 & 33 & 38 & & 9 & 18 & $0 \cdot 003 \ddagger$ \\
RSV & 88 & 100 & & 49 & 100 & $0 \cdot 004 \ddagger$ \\
Total & & & & & \\
\hline
\end{tabular}

*Number of children with ARI (positive) or without ARI (negative) in each age group.

$\dagger N S$, Not statistically significant.

$\ddagger P \leqslant 0.05$ by $\chi^{2}$ test of children with ARI compared to children without ARI (\%), respectively. incidence of respiratory infection in children with ARI and without ARI was observed during the summer-autumn period.

The distributions of respiratory viruses identified from children with ARI and children without ARI by age group are shown in Figs 2 and 3, respectively. In the ARI group, two types of virus (RSV and Ad) were predominantly found in the $<1$ year age group. RSV was also increasingly found in the 3 to $<4$ years age group (Fig. 2). Higher frequencies of RSV (41\%) and Ad (22\%) in infants with ARI were statistically significant when compared with infants in the ARI-free group (17 and $0 \%$, respectively). The frequency of RSV $(43 \%)$ in children with ARI from the 3 to $<4$ years age group was highly significant when compared with ARI-free children from the same age group (18\%; Figs 2 and 3).

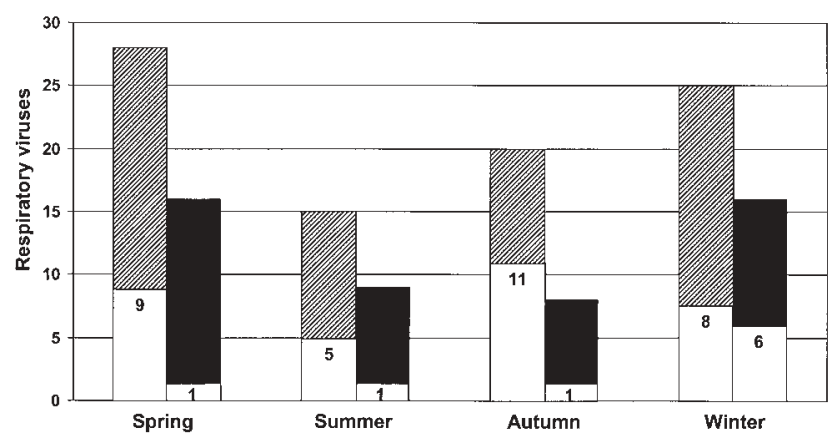

Fig. 1. Number of children with respiratory viruses by seasonal period. Hatched bars, cases with ARI; filled bars, controls without ARI; empty bars, RSV. 


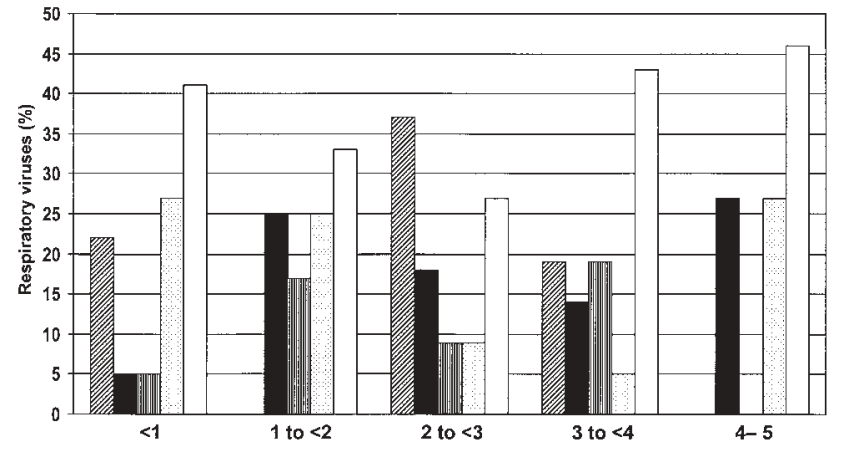

Fig. 2. Distribution of positive respiratory viral types in Mexican children with ARI by age group. Diagonally hatched bars, Ad; filled bars, IA; vertically hatched bars, IB; dotted bars, PI; empty bars, RSV.

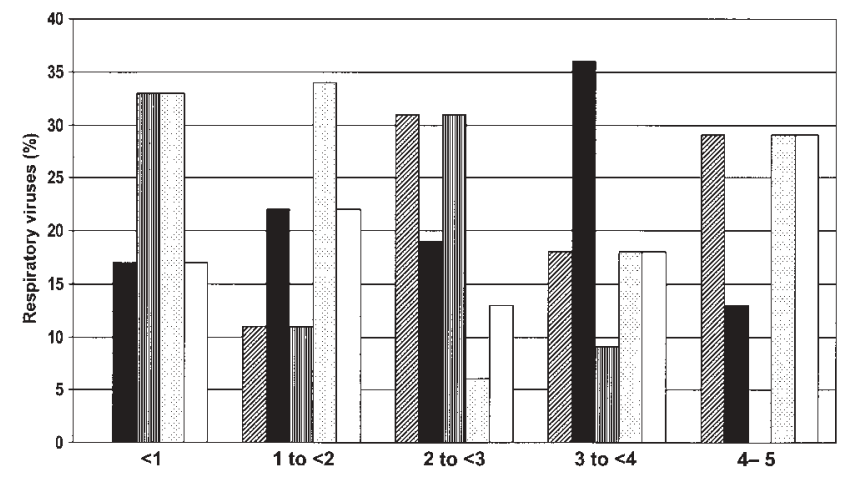

Fig. 3 Distribution of positive respiratory viral types in Mexican children without ARI by age group. Diagonally hatched bars, Ad; filled bars, IA; vertically hatched bars, IB; dotted bars, PI; empty bars, RSV.

\section{DISCUSSION}

In developing countries, RSV has been frequently incriminated in both upper and lower respiratory tract infections in children under 6 months of age (McIntosh, 1990, 1991). In Mexico, morbidity and mortality rates are the only epidemiological indicators of influenza disease that are reported by the Ministry of Health (Secretaría de Salud, 1999). In this study, even though nasopharyngeal samples in the majority of subjects with ARI were negative for viral infections (91/179), RSV was the viral agent found most frequently $(38 \%)$ in this group. These results are in line with previously published reports (Schmitz et al., 1985; McIntosh, 1991; Videla et al., 1998; Chan et al., 1999; Nelson et al., 1999). Adenoviruses are commonly isolated from children $<4$ years of age (65\%; Videla et al., 1998). As the main cause of ARI, adenoviruses are responsible for $5 \%$ of clinical cases and $10 \%$ of cases requiring hospitalization in this group of children (Schmitz et al., 1985; Videla et al., 1999). Results from Nezahualcóyotl City showed that adenoviruses were the second most frequently found viral agents in ARI cases $(19 \%)$. The parainfluenza viruses, specifically types 1,2 and 3 , are well-known as major aetiologies of croup (50\%) in children $<2$ years of age (McIntosh, 1991; Gorman et al.,
1992; McIntosh et al., 1993) and in this study they were detected in $17 \%$ of isolates. The influenza viruses, specifically groups $\mathrm{A}$ and $\mathrm{B}$, are frequently found as aetiological agents of both upper and lower (pneumonia) ARI in patients of all ages, but more specifically in children (McIntosh, 1990; McIntosh et al., 1993; Chan et al., 1999). The frequency of IB as a percentage of total viruses isolated in this study was lower than expected, with a frequency of $10 \%$ in children with ARI and $18 \%$ in ARI-free children.

Possible explanations for these findings are as follows: (1) the results relate to differences in detection tests performed for the five main respiratory viruses (IA, IB, PI, RSV and Ad) and did not include other possible agents that cause ARI in children; (2) virulence patterns differ among these viruses and show RSV to be the most virulent among those studied; (3) transmission route differs between respiratory viruses, as most of them are usually transmitted by direct contact with contagious secretions and by air droplets, but RSV infection can also be acquired through the conjunctiva, which increases its frequency; (4) epidemiological rates differ between respiratory viruses isolated in infants, with RSV being both the most frequently found and the cause of the most severe infectious disease.

Viral infection in children with ARI was more frequent and highly significant when compared with infection in ARI-free children from this particular suburban community of Nezahualcóyotl City. Viral isolates were obtained from $49 \%$ of 179 children with ARI. The highest frequencies of respiratory viruses were found in infants (group A: $56 \%$ ) and in children from 2 to $<3$ years of age (group C: $54 \%$ ). RSV was the most frequently isolated virus $(38 \%)$, followed by adenovirus (19\%). As previously mentioned, viruses are frequently isolated from infants and the frequency may increase at 2-3 years of age or older due to greater contact with other children, e.g. attending day-care centres or kindergartens.

In the ARI-free group, older children showed higher frequencies of isolated viruses than the group of children with ARI, in which the highest frequencies were observed in younger children (group A: $<1$ year of age). It is interesting that respiratory viruses were isolated from ARI-free children and there are a number of reasons that may explain this: (1) viruses could have been isolated on any specific day in the 2-7 day incubation period; (2) viral pathogens were shown to have reduced virulence, showing that the pathogens have been attacked by normal host defences that have led to a reduction in viral propagation and disease severity; (3) viruses had a symbiotic relationship with the host; (4) the influenza virus (groups A and B) mainly infects children and causes mild clinical events, many of which are usually considered to be asymptomatic.

There are some reports that emphasize variation of respiratory viral infections over time (Thomas et al., 1994; Stensballe, 2002). Results from the present study showed that higher viral incidence in children with ARI was observed during the winter-spring period than during the summer- 
autumn period. If research findings that show that RSV had the highest viral incidence in children with ARI are taken into account, it is feasible to suggest that the incidence of RSV infection was seasonally affected by environmental factors (low temperature and humidity).

In Mexico, there are very few clinical reports that concern the contribution of these viruses to severe lower respiratory infections. Two specific reports from a local hospital showed that RSV, IA and Ad are the most frequent types of respiratory virus found in their patients (children $<5$ years of age and adults) with chronic pulmonary illnesses (Manjarréz \& Thompson, 1992; Manjarréz et al., 1999).

As the main objective of this study was to estimate the comparative viral prevalence among the paediatric population with and without ARI, a selection bias in terms of the children seeking medical attention at the specific health centre is expected.

It seems that more epidemiological surveillance is needed to track viral isolates seasonally and annually. The study results show viral incidence to be high. Further study of clinical isolates is recommended to identify the viral types and subtypes involved, in order to improve treatment outcome by more specific prescription.

\section{ACKNOWLEDGEMENTS}

We thank Maritoña Ramírez-Pérez for his excellent technical assistance. We also thank Patricia Cravioto, Guadalupe S. García de la Torre and Fernando Galván for their helpful comments. We are grateful to Ian Shepherd for assistance in the preparation of this manuscript. This study was supported by research grants from the Dirección General de Asuntos del Personal Académico, Universidad Nacional Autonóma de México, Mexico City, DGAPA-UNAM no. IN207594, DGAPA-UNAM no. IN203397 and DGAPA no. IN215101.

\section{REFERENCES}

Benguigui, Y. (1988). Magnitud y control de las infecciones respiratorias agudas en los niños. Salud Pública Méx 30, 364-365 (in Spanish).

Benguigui, Y. (1996). Control de las infecciones respiratorias agudas (IRA). In Acciones de Salud Materno-infantil a Nivel Local: Según las Metas de la Cumbre Mundial en Favor de la Infancia. Edited by Y. Benguigui, S. Land, J. M. Paganini \& J. Yunes. Washington, DC: $\mathrm{PAHO} / \mathrm{WHO}$ (in Spanish).

Chan, P. W., Goh, A. Y., Chua, K. B., Kharullah, N. S. \& Hooi, P. S. (1999). Viral aetiology of lower respiratory tract infection in young Malaysian children. J Paediatr Child Health 35, 287-290.

Cravioto, A., Eslava, C., López-Vidal, Y. \& Cabrera, C. R. (1998). Strategies for control of common infectious diseases prevalent in developing countries. Methods Microbiol 27, 587-594.

Degré, M. (1986). Interaction between viral and bacterial infections in the respiratory tract. Scand J Infect Dis Suppl 49, 140-145.

Denny, F. W., Jr (1995). The clinical impact of human respiratory virus infections. Am J Respir Crit Care Med 152, S4-S12.

Douglas, R. M. (1990). The impact of socio-economic factors on respiratory infections in children. Bull Int Union Tuberc Lung Dis 65, $8-11$.
Gorman, O. T., Bean, W. J. \& Webster, R. G. (1992). Evolutionary processes in influenza viruses: divergence, rapid evolution, and stasis. Curr Top Microbiol Immunol 176, 75-97.

Graham, N. M. (1990). The epidemiology of acute respiratory infections in children and adults: a global perspective. Epidemiol Rev 12, 149-178.

Hosmer, D. W. (1992). Computer analysis of health sciences data; course PH 744. Amherst, MA: University of Massachusetts.

Makelä, M. J., Puhakka, T., Ruuskanen, O., Leinonen, M., Saikku, P., Kimpimäki, M., Blomqvist, S., Hyypiä, T. \& Arstila, P. (1998). Viruses and bacteria in the etiology of the common cold. J Clin Microbiol 36, 539-542.

Manjarrez, M. E. \& Thompson, O. (1992). Aislamiento del virus sincicial respiratorio en niños hospitalizados por infecciones respiratorias agudas. Rev Inst Nal Enf Resp Méx 5, 28-34 (in Spanish).

Manjarrez, M. E., Montufar, E., Rosete, D., Chapela, R., Calderón, I. \& Villalba, J. (1999). Infección en pacientes con inflamación y enfermedad obstructiva crónica o asma. Rev Inst Nal Enf Resp Méx 7, 101-106 (in Spanish).

McIntosh, K. (1990). Creation of a research program to determine the etiology and epidemiology of acute respiratory tract infections among children in developing countries. Rev Infect Dis 12 (Suppl. 8), S861S869.

Mclntosh, K. (1991). Pathogenesis of severe acute respiratory infections in the developing world: respiratory syncytial virus and parainfluenza viruses. Rev Infect Dis 13 (Suppl. 6), 492-500.

McIntosh, K., Halonen, P. \& Ruuskanen, O. (1993). Report of a workshop on respiratory viral infections: epidemiology, diagnosis, treatment, and prevention. Clin Infect Dis 16, 151-164.

Nelson, J. K., Shields, M. D., Stewart, M. C. \& Coyle, P. V. (1999). Investigation of seroprevalence of respiratory virus infections in an infant population with a multiantigen fluorescence immunoassay using heel-prick blood samples collected on filter paper. Pediatr Res 45 , 799-802.

Schmitz, H., Wigand, R. \& Heinrich, W. (1985). Worldwide epidemiology of human adenovirus infections. Am J Epidemiol 117, 455-466.

Secretaría de Salud (1999). Instituto Nacional de Estadística, Geografía e Informática (INEGI), Dirección General de Estadística e Informática. Estadísticas de Morbilidad y de Mortalidad para las Enfermedades. México: DGE-SSA (in Spanish).

Stensballe, L. (2002). An epidemiological study of respiratory syncytial virus associated hospitalizations in Denmark. Respir Res 3 (Suppl. 1), S34-S39.

Thomas, E., Margach, M. J., Orvell, C., Morrison, B. \& Wilson, E. (1994). Respiratory syncytial virus subgroup B dominance during one winter season between 1987 and 1992 in Vancouver, Canada. J Clin Microbiol 32, 238-242.

Videla, C., Carballal, G. \& Kajon, A. (1999). Genomic analysis of adenovirus isolated from Argentinian children with acute lower respiratory infections. J Clin Virol 14, 67-71.

Videla, C., Carballal, G., Misirlian, A. \& Aguilar, M. (1998). Acute lower respiratory infections due to respiratory syncytial virus and adenovirus among hospitalized children from Argentina. Clin Diagn Virol 10, $17-23$.

Working Group on ARI, Respiratory Disease Committee (1993). Acute respiratory infections: conclusions of an IUATLD workshop. Tuber Lung Dis 4, 2-5.

World Health Organization (1993). Programme for the Control of Acute Respiratory Infections. WHO/ARI/93.25. Geneva: World Health Organization. 